\title{
Empathy: Concepts, Theories and Neuroscientific Basis
}

\author{
Josip Bošnjaković ${ }^{1}$, Tanja Radionov ${ }^{2}$ \\ ${ }^{1}$ Catholic University of Croatia, ${ }^{2}$ Counseling office St. Joseph
}

\begin{abstract}
Summary - Empathy is an important concept in contemporary psychology and neuroscience in which numerous authors are dedicated to research the phenomena. Most of them agree on the significance of empathy and its positive impact on interpersonal relationships, although certain negative aspects of empathy also exist. From psychological and biological point of view, empathy is an essential part of human survival and successful living in social groups. This paper introduces an overview of empathy, including history of concept starting with the notion of Einfühlung, as well as beginning of studying and defining empathy, contemporary approach, components of empathy and its evolutionary and neuroscience background, empathy measures, development of empathy through training, and finally, the other side of this generally positive concept regarding interpersonal relationships. We also gave notion to further research issues in this field.
\end{abstract}

Key words: empathy, affective empathy, cognitive empathy, social-cognitive neuroscience, empathy measures, empathy training, selfish empathy

Copyright @ 2018 KBCSM, Zagreb

e-mail: alcoholism.kbcsm@gmail.com•www.http://apr.kbcsm.hr

\section{Introduction}

People are extremely social beings. They share their lives with others and their lives are formed through social relationships. The way people engage in social interactions depends highly on their understanding of other peoples mental state, especially emotions, desires, wishes, thoughts, behaviours and intentions. Empathy enables us to understand our social environment at any given moment, as well as to predict other people's behavior, which

Correspodence to:

Catholic University of Croatia

Psychology Department

Ilica 242, 10000 Zagreb

josip.bosnjakovic@unicath.hr ensures a successful interaction. Empathy is one of the personality traits which makes us social beings. Besides recognizing others emotions, and reflecting upon them, we are also capable of emotion sharing and reacting. Empathy plays a key role in our emotional and social interactions, it is essential for healthy coexistence among people, mutual understanding, and cooperation. It affects our motivation through prosocial behaviour, altruism, compassion and caring for others, it inhibits aggression, and is the foundation for morality. Scholars in various scientific areas such as philosophy, psychology, medicine, neuroscience etc. are attracted to the phenomenon of empathy. 
The aim of this paper is an overview of the concept of empathy in the field of psychology and neuroscience from its very beginnings until today in order to provide a clearer view of the phenomenon. This research includes essential elements of understanding empathy as a whole. Paper's starting point is the review of the beginning of empathy approach, as well as contemporary definitions and areas of empathy. The most common distinction between components of empathy in various studies is affective empathy vs. cognitive empathy, so these components are specifically explained having in mind that empathy integrates both components. Many important phenomena similar to empathy are also explained. Clearer understanding of empathy includes overview of its evolutionary and neuroscience background as well as other factors related to empathy (neurochemical, contextual, personality, and psychopatological). Since the beginning of empathy research, empathy measures have also developed, and are enlisted in this paper. Depending on whether empathy is defined as a personality trait, ability, virtue or a process, possibilities of developing empathic abilities through training is discussed. Although most researchers pointed out the positive side of empathy, there are some that highlight the other side of empathy, which we also analyzed. Finally it is important to point out the future empirical issues in empathy research field.

\section{The beginnings of empathy research}

Even though empathy was a concept in which various scientists outside psychology have been involved with, psychological aspect of empathy came into focus when the concept of empathy was defined from psy- chological point of view. Late in the $19^{\text {th }}$ century, as German aesthetics moved from the objective world to the working of the mind as accounting for the essential feature of human aesthetic contemplation of the world, in 1873, Robert Vischer suggested the term Einfuiblung, the predecessor of empathy, to mean humans' spontaneous projection of real psychic feeling in to the people and things they perceive [1]. In the beginning of $20^{\text {th }}$ century (in 1903), Lipps developed Einfüblung theory for psychology "from a psychological, nonmetaphysical perspective" and through "a phenomenological method". He believed that people knew and responded to each other through Einfüblung, which was preceded by projection and imitation, and that as imitation of affect increases, Einfühlung increases [1].

The term empathy was coined by Titchener [2] as a rendering of Einfüblung, which he defined as "process of humanizing objects, of reading or feeling ourselves into them" [3]. A reactive-projective perspective and an emphasis on perceptive awareness of another person's affect or sharing of feelings were apparent in this view [1]. The word empathy derives from Old Greek - $\mu \pi \alpha \theta \varepsilon \iota \alpha(\varepsilon \nu-$ in + $\pi \alpha \theta \varepsilon \iota \alpha$ - feeling, emotion).

Husserl describes empathy as intersubjectivity, a capacity that emerges through putting ourselves into the shoes of others [4]. The word, intersubjectivity, describing the main reality of empathy as an encounter between two subjects, is extremely important. Empathy denotes a specific form of basic intentional experience, as Husserl [5] argues: "The intentionality in one's own ego that leads into the foreign ego is the so-called empathy". Stein [6], a student of Husserl's, similarly describes empathy as a process by which "foreign subjects and their experience are given to us, [we take them in, and as a result] for- 
eign experience is comprehended" [4]. For her, people are innately open and receptive to one another; we absorb each other's thoughts and feelings, and in so doing make them our own. Stein defines empathy as an experience sui generis, which she describes ,as the experience (Erfahrung) of foreign consciousness in general" [7].

Empathy theories in psychology were largely influenced by the aforementioned approaches up until Mead [8], whose definition of empathy is considered one of the basic ones today, describes it as an ability to understand other person's situation (taking the role of the other). Mead saw empathy as a willingness or tendency to put one-self in another person's place and to modify one's behavior as a result. He recognized the self-other differentiation in empathy and added a cognitive component, an ability to understand, to empathize. He also argued that the role-taking ability is the key variable in moral growth [1, 9]. The person who is capable of imagining a certain situation becomes aware of the possible consequences of that behavior for other people, and that also makes him capable of moral responsibility. Taking others into consideration and pondering about their feelings and thoughts is a vital part of the process of empathy.

Empathy became a very important concept for psychotherapists and counseling psychologists, especially for psychoanalytic and humanistic theorists. In psychoanalytic theory empathy is seen as a part of therapy cure [10]. Freud [11] wrote that empathy is essential in taking perspective of the other person's mental life and it's a process that has an important role in our understanding of what is inherently foreign to our ego in other people. Empathy is putting self into the other person's shoes, either consciously and unconsciously [12]. Fenichel [13] views empathy as a process which includes two acts, first, an identification with the other person, and the second, an awareness of one's own feelings after the identification and an awareness of others feelings [14]. Kohut defines empathy as a method used in psychoanalytical research, pointing out the fact that being empathic in therapist-patient relationship is not enough to improve someone's situation. Empathy is merely a sign of an adequate therapy action within therapist-patient relationship, and it also helps the therapist to progress in the direction which may be helpful [15]. He defines empathy as "vicarious introspection" [16, 10]. Beres and Arlow [17] say that a therapist would be able to empathize with their patient's feelings only if and when he could become consciously aware of the patient's unconscious wishes, conflicts, fantasies, and other mental contents [12]. According to Basch [18] some analysts believe that empathy involves resonating with the patient's unconscious feelings and experiences within them, while the integrity of therapist's self remains intact [12].

In humanistic psychology, the meaning of empathy is taken into serious consideration, and thanks to Rogers's influence [19, 20, 21], empathy has been approached by researchers with scientific methods. Rogers [22] perceives empathy as a necessary and sufficient condition for psychological change, has been a key concept in understanding why and how therapy works, and has been seen as a way of knowing and understanding another person or an object. The therapist uses empathy to understand the client's mental state and attempts to communicate that experience. He also explains empathy by describing an empathic person as seeing the situation "as if one were the other person" [22]. 
Duan and Hill [1] point out that the term empathy has been used to refer three different constructs that may or may not overlap with each other. First group of theorists refer to empathy as a personality trait or ability: to know another person inner experiences or to perceive the emotions of the other person. The implicit assumption underlying this view is that some individuals are more empathic than others, either by nature or through development [23-29, 9, 30, 8]. These authors have defined empathy by using terms such as "empathic disposition" [9], "interpersonal orientation" [21], "responsiveness to the feelings of another person" [31], and "dispositional empathy" [32]. Second group of theorists saw empathy as a situation specific cognitive-affective state [33, 34, 35, 29, 19-22]. From this perspective, empathy is commonly defined as responding "vicariously" to a stimulus of the other person [36-38], assessing other's private world as if it were one's own [22, 39], a match between the observer's and the other person's affect or cognition [40,38], or the degree to which a therapist understands and feels client experiences [33, 41, 39]. The underlying implicit theory for this consideration of empathy is that regardless of one's developmental level of empathy, empathic experience varies by the situation. Third group of theorists are concerned with how empathy is experienced by therapists and clients in given situations have conceptualized empathy as a multiphased experiential process. They consider the moment-to-moment experience of empathy and examine the processes involved in producing and communicating an empathic state [33, 18, 42, 29, 37, 43, 24]. Barrett-Lennard's [33] cyclical model (identifying three phases of empathy: empathic resonation, expressed empathy, and received empathy), Rogers's [44] “temporarily living in” process (involving sensing the client's inner world and communicating that sensing), Kohut's [45] two-step empathy in psychoanalytic cure (understanding-explaining sequence), and Gladstein's [46] "multistage interpersonal process" (including emotional contagion, identification, and role-taking). This view of empathy implies that empathy involves a sequence of experiences. For better understanding, it is necessary to avoid using the general term of empathy and use instead the specific terms of dispositional empathy, empathic experience, and empathic process to specify which construct is being referred to.

\section{A contemporary approach to defining empathy}

In contemporary scientific approach, empathy is the major topic of social, developmental, and personality psychology as well as other disciplines, such as neuroscience, clinical psychology, psychotherapy, and various health professions [47]. Empathy is very complex and multidimensional phenomenon. It is viewed as an interpersonal process and individual ability [48], as a personality trait [49], as capacity or competency [50], as response or reaction to observing another's experiences [51], and as interpersonal behavior [52]. It is also described as knowledge that changes the empathic person, brings new sympathy, new feelings, as well as new cognition and other forms of intersubjectivity [53].

It is of great importance of integrative empathy approach which connected folklore conception of empathy with explanations offered by social psychology, developmental sciences and neuroscience. Authors conjoin social and cognitive psychology terminology of empathy in order to connect them with neuroscience more easily [12]. Singer and 
Lamm [54] had similar ideas. They claimed that a lot of research in social psychology had been studying which perceptive, emotional and cognitive mechanisms helped people to put themselves into others' shoes. After a while, neuroscience started to deal with the same subject with all complexity of this psychological phenomenon, as well as with methodological challenges of putting this sensitive and socially dependent concept to scientific framework. Some of the challenges include the ability to both control, and repeat experiments.

The important quantitative review and conceptual analysis of empathy gave Hall and Schwartz [47] which used random selection method to analyze 393 studies published between 2001 and 2013, and 96 studies published in 2017. They found that empathy is most commonly seen as a multidimensional concept divisible into dimensions, facets, factors, types, subscales, substrates, processes, aspects, etc. From 2001 to 2013 33\% of the authors cited multidimensionality while in 2017 it increased to $52 \%$. In 2017, among just those authors who gave a conceptual definition, $76 \%$ cited multidimensionality using the most common distinction between affective and cognitive empathy. The conceptual definitions that were provided varied enormously which illustrates that authors fundamentally disagreed on what warrants the label "empathy." Some authors gave definitions of empathy with one defining feature such as prosocial concern for others welfare, sympathy, understanding others feelings. The second group of authors gave definitions with two defining features, such as sharing and understanding others feelings, ability to understand others feelings and perspective, and ability to respond to affective experience of the other person. And finally, there are definitions with more than two defining features, such as experiencing others emotions, perspective taking, prosocial concern, acting compassionately or otherwise appropriately to the situation, accurate perception of others emotions and other states.

It is safe to say that the term empathy is applied to various phenomena which cover a broad spectrum from feeling of concern for other people that create a motivation to help them, experiencing emotions that match the other person's emotions, knowing what the other is thinking or feeling, to blurring the line between self and the other [14]. Therefore, empathy is not an exclusive phenomenon, meaning all or nothing, but is more likely made of different forms and intensities of showing and experiencing empathy, ranging from simply being affected by others distress to completely understanding them and foreseeing the possible consequences [55].

Decety and Jackson [12] described three functional components of empathy which dynamically interact to produce the experience of empathy. First, affective component, which includes sharing emotions; second, the awareness of self and the other with specific mechanisms for differentiate between the two, and third, cognitive component including understanding others perspective. Lamm, Rütgen and Wagner [56] claim that empathy means isomorphic emotion sharing, which may be caused either by direct observation, or by pure imagination of others emotions, meaning that the empathic person is aware of the fact that the source of such emotions are within the other person.

Batson [57] enlisted eight aspects of empathy: 1. Knowing another person's internal state, including thoughts and feelings; 2. Adopting the posture or matching the neural responses of an observed other; 3. Coming 
to feel as another person feels; 4. Intuiting or projecting oneself into another's situation; 5 . Imagining how another is thinking and feeling; 6. Imagining how one would think and feel in the other's place; 7. Feeling distress at witnessing another person's suffering; and 8. Feeling for another person who is suffering.

\subsection{Components of empathy}

In a number of studies empathy has been identified as primarily an affective phenomenon (affective empathy), referring to the immediate experience of the emotions of the other person, as primarily cognitive phenomenon (cognitive empathy), referring to the intellectual understanding of others experience, and a third view holds that empathy contains both affective and cognitive components.

\subsubsection{Affective empathy}

Some definitions of empathy include only its affective component, for example, "A sense of similarity between the feelings one experience and those expressed by others" [55]; "affective state, caused by sharing of the emotions or sensory states of another person" [58]. This aspect of empathy focuses on emotional processes of empathy and defines it through experiencing and sharing emotions. Discussing affective empathy implies being aware of the complexity of human emotions which ranges from the most beautiful to the most difficult human states. Although most studies deal with cognitive aspect of empathy, the etymology of the word implies that its nature surpasses pure cognition and also refers to others emotional state which is related to one's adjustment to social environment and surroundings [59]. Raboteg-Šarić [60] describes empathy as emotion coupling between one's feelings and of the other, and states that many researchers agree that affective component is what is inherent in empathy.

Empathy includes both negative feelings, which are more frequently studied [61], and positive feelings [62]. Empathic happiness is described as "the tendency to vicariously experience feelings of goodwill and pleasure in response to someone else's display of positive emotion" [62]. According to Walter [63], the concept of affective empathy includes the following features: "a) an affective state that is b) elicited by the perceived, imagined, or inferred state of the affective state of another; c) is similar (isomorphic) to others affective state; d) is oriented towards the other; and e) including at least some cognitive appreciation of the other's affective state, comprising perspective taking, self-other distinction, and knowledge of the causal relation between the self and the other's affective state".

The advantage of focusing on emotion sharing is in the possibility of measuring them empirically and to put them in correlation with neural processes. That can only be applied to certain emotions, such as pain, suffering, disgust, confusion, pride, shame, and guilt. Other more complex and social emotions including love or other mixed feelings represent a much bigger challenge for empirical study [64].

\subsubsection{Cognitive empathy}

Many definitions of empathy include only its cognitive component, for example "attempt by one self-aware self to comprehend un unjudgementally the positive and negative experiences of another self" [65]; "act of constructing for oneself another person's mental state" [9]. This approach to empathy gives advantage to cognitive processes, which 
include understanding others feelings, roletaking, seeing the world as the other does.

In its core, cognitive empathy means "setting aside one's own current perspective, attributing a mental state (or attitude) to the other person, and then inferring the likely content of their mental state, given the experience of that person" [66]. "Cognitive aspect of empathy includes understanding, awareness of others and circumstances, or awareness of how something that is happening can affect a certain person. Many theorists who emphasize this aspect of empathy believe that cognitive empathy precedes affective empathy" [60].

Cognitive empathy as an ability of understanding other's feelings is closely related to theory of mind which refers to represent and understand the mental state of others in general [67]. Mental states include beliefs, desires, intentions, as well as emotions and affective states. So, "mentalizing about affective state of others can be therefore called emotional theory of mind- which is more or less synonymous with cognitive empathy" [63]. Also, cognitive empathy is often compared with imitation, altruism and moral cognition [68].

\subsubsection{The integration of affective and cognitive empathy}

It is important to point out that during development of the concept of empathy, the authors gave emphasis on different things, and it is only nowdays, after many research, that theorists see empathy as an inclusive concept, not only because of its interdisciplinary nature, but also due to its affective and cognitive components and all that it conveys. Strayer [69] notes that affective component is the essence of empathy, and the cognitive component is a process through which that essence comes into being. Definitions of empathy which includes both cognitive and affective dimension note that "although empathy entails an emotional resonance between the empathizer and the object of empathy, it also is characterized by the maintenance of a clear cognitive and experiential boundary between the two, such that the empathizer can always distinguish between his/her own thoughts and feelings and those of others" [70]. Some definitions of empathy which includes both components are: "The capacities to resonate with another person's emotions, understand his/her thoughts and feelings, separate our own thoughts and emotions from those of the observed and responding with the appropriate prosocial and helpful behavior" [71]; "The act of perceiving, understanding, experiencing and responding to others emotional states or ideas" [72]. Non-verbal expressing empathy, encompassing both cognitive and affective component, is thought of as an advanced form of empathy [15].

\subsection{Phenomena related to but distinct from empathy}

Studies discuss several phenomena which are related to empathy but at the same time distinct from it. Such phenomena are mimicry, emotional contagion, sympathy, compassion, empathic concern, and empathic pain or personal distress. Mimicry is described as the tendency to automatically synchronize affective facial expressions, vocalizations, body postures, and movements with those of the other person [73]. It has a role as a low-level mechanism contributing empathy. When an observer perceive others affective facial expressions, such as a smile, or different bodily concomitants, corresponding affective expression or bodily concomitants result in the observer. Mimicry seems to serve a so- 
cial function in increasing rapport and fondness between self and the other [74, 54, 63, 75]. Emotional contagion is tendency to "catch" others emotions and has been labeled as "primitive empathy" [76]. For example, babies start crying when they hear other babies crying- long before they develop a sense of self separate from others. Emotion contagion may function as one core component of empathy. Neither mimicry nor emotional contagion are a full experience of empathy because empathy crucially depends upon self-awareness and self-other distinction $[76,74,54,63,75]$.

In empathy, sympathy, empathic concern, and compassion, affective changes are induced in the observer in response to the perceived or imagined affective state of the other person. However, while empathy involves isomorphic emotions to those of the other person (empathizing with a sad person will result in sadness in self), sympathy, empathic concern, and compassion do not necessarily involve shared emotions (encounter with sad person will result in either pity or compassionate love and care, but not sadness). In empathy observer's emotions reflect affective sharing ("feeling with" the other person) while in sympathy, empathic concern, and compassion, observer's emotions are inherently other-oriented ("feeling for" the other person) with motivation to help, care and relieve others suffering [77, 74, 78, 54].

Empathy is closely related to pro-social, altruistic, and other-oriented motivations. It is considered as a first necessary step in process that begins with emotional contagion which underlies affect sharing, followed by understanding of others emotions, which then motivates other-related feelings such as sympathy, empathic concern, and compassion, which may further promote engagement in prosocial and helping behaviour [77, 54].

Empathic pain or personal distress refers to strong negative affective state and response to others suffering, followed by desire to turn away from the situation in order to protect self from extremely negative emotions, and consequently feel better. This phenomenon is more self-centered than other-oriented [78, 63]. Batson [57] and Eisenberg [79] confirmed that people who feel compassion and empathy in certain situation help more often than the ones who suffer from empathic pain or distress. Empathic pain or distress results in negative emotions, it is related to withdrawal and disengaging from certain relationships, and if it is experienced chronically, it may have negative health outcomes.

\section{The evolutionary origins of empathy}

Humans are social beings and their survival depends greatly on their social interactions, forming relationships and mutual connections, as well as accurate social judgements. It is highly unlikely that empathy is a result of a random mutation and emerged without having some kind of evolutionary development in humans. Throughout evolution, organization of neural activities of the brain evolved, which enabled the occurrence of certain important human behaviours, such as empathy. Empathy is significant because it plays an important role in the survival of the species, and improves the likelihood of staying in a social group. That is why during evolution people developed several separate neural systems, combination and cooperation of which enables complex behavior within social interactions, as well as the development of both emotional and social intelligence. 
Empathic concern as an aspect of human empathy includes taking care of the offspring, caring for others, emotional and social connection with others, and prosocial and altruistic behavior. Some forms of empathy can be found in animal behavior, especially in primates such as taking care of the offspring, certain forms of social intelligence and play, which are considered evolutionary predecessor of empathy. Taking care of the offspring is evolutionally extremely important because of its contribution to genetic fitness (kin selection) and it is genetically based. However, what is specific to humans is development of prefrontal cortex which led to development of self-awareness, other-awareness, emotion self-regulation, speech ability and understanding language, and mutual emotion-sharing through language and conversation, as well as ability of reflection and metacognition - these all being processes and abilities which developed alongside with empathy, which all leads to prosocial behavior and altruism among humans. That means humans show affection both to their offspring, to other people who are non-kin (because it provides reproductive advantage), and even feel empathy toward different species (animals). Besides evolutionary development of the cortex, other biological systems vital for empathy evolved: autonomic nervous systems (sympathetic and parasympathetic division), and endocrine system which both have an important role in our emotions, and formation of relationships and pair-bonding; as well as limbic system (hypothalamus, hippocampus, amygdala, etc.), which has a role in emotion evaluation and regulation. It is obvious that evolution of various neurobiological mechanisms required for empathy occurred, as well as the ones for perception, understanding, prediction, and responding to oth- ers mental states which are all interconnected $[14,12,55,74]$.

Affective empathy in humans probably occurred as a result of kin selection, reciprocal altruism and sexual selection, since it inspires altruistic behavior and morality, and also inhibits violence and aggression, stimulates group cohesion, and ingroup-outgroup distincion. On the other hand, cognitive empathy developed due to increasing social complexity in groups, which is conditioned by the advanced reciprocal exchange, cooperation and the likelihood by being deceived. It involves the ability to predict other people's behaviour, to maintain conversations, develop social expertise, to lie and to realize when someone is lying ("cheating detection") [74].

Indicators of evolutionary development and genetic predisposition of certain components of empathy would be explained through the development of humans from birth, and will be mentioned in reviews of neuroscience research of each empathy component.

\section{Social-cognitive neuroscience of empathy}

Neuroscience researches of empathy began about 15 years ago and have shown that there is no universal neural empathy model, but that empathy includes various parallel brain processes, since it is a complex and multi-level affective-cognitive-behavioral phenomenon. Empathy is an extensive and multidimensional concept that has evolved throughout the study history, changed its definition and determination depending on the more prominent component, affective, cognitive, or motivational. These findings had a key role in directing neuroscience researches of empathy to its specific components. 
Decety and Jackson [12,80] pointed out three primary components of empathy: 1 Emotional response to the other person, which includes emotion sharing; 2. Cognitive capacity of taking others perspective, and 3. Emotion regulation which is regulation mechanisms that enable distinguishing self from the other, and one's own emotions from others. In contemporary neuroscience studies, especially the ones in which functional magnetic resonance imaging, fMRI is used, researchers attempted to determine the neural basis of each component of empathy enlisted by Decety and Jackson [12, 80], along with their interconnections, having in mind the complexity of the neural process in the brain during empathy.

\subsection{Emotion sharing between self and others}

\section{Perception and action coupling}

Studying perception of other people's behaviour is significant as it plays a key role in understanding other people's emotions and intentions. Shortly after birth, a newborn has spontaneous motor reactions and imitation, which enables it to communicate with those around, as well as perception and action coupling $[81,12]$. Behavioral manifestation of empathy can be seen early in child's development. From as early as 6 months old, an infant shows preference of certain people and characters, while at 1.5-2 year-olds a child can manifest prosocial behavior and affection to the other person in pain, or even sympathy to someone without expressing their emotions [81].

Perception-action model, PAM by Preston and de Waal [82] discusses perception and action coupling between the observer and the observed. By perception of others behavior, automatically activates neural representations (autonomic and somatic response) of that behavior in the observer. This includes premotor cortex, parietal cortex, supplementary motor area, and cerebellum $[81,12,80,55$, $82,63,75]$.

The discovery of somatosensory neurons, so-called "mirror neurons", provides a physiological mechanism for direct link between perception and action. Mirror neurons were discovered accidentally in macaque monkeys' ventral premotor cortex in 1996 [83]. They were later also found in other brain regions such as frontal intraparietal region and primary motor cortex, as well as in the emotional centers in the brain. These neurons are called mirror neurons because they activate in the observer during a specific motor action and perception which are active in the person experiencing it. In other words, they reflect automatic transformation of the other person behavior in corresponding neural representation in the observer and create a functional bridge between first-person and third-person information, between self and the other. This is what happens in empathy, as well as in other similar processes such as understanding, imitation, and mentalizing [81, 84, 85, 63].

\section{Emotion sharing}

Studying emotion sharing among humans is very important in understanding the concept of empathy, especially its affective component. Understanding others' emotional signals has an important adaptive function, as well as in the formation and maintenance of social interactions and relationships. From birth we express the need to engage in relationships with other people. Newborns express distress and cry whenever they hear other newborns crying. Early in childhood, infants show the ability of emotional reso- 
nance and discriminate different facial expressions of emotions, which plays an important role in developing of attachment as one of the precursor of empathy $[81,12,86]$.

Perception of the other person's emotion activate in observer's neural mechanisms which trigger the same emotion in him. Likewise, if we observe a facial expression of a certain emotion, the similar expression is activated in the observer's face, as well as the emotion itself. So, mirror neurons are also involved in perception of others emotion. They are present in somatosensory cortex, anterior frontal gyrus in the right hemisphere, and posterior parietal cortex [77, 81, 86, 63].

Many researchers of empathy are focused on studying the observation of pain in others, in which people are observing pain in the other person or experienced pain themselves. Pain expression offers a key signal which may motivate help-oriented behavior in others, i.e. activate empathy. It has been established that observing a person who is in pain and suffering is related to neural response which processes motivational-affective and sensory dimension of pain in the observer. A so-called "pain matrix" is activated which includes dominantly anterior cingulate cortex, anterior insula in the right hemisphere, as well as primary and secondary somatosensory cortex. Besides, brainstem and cerebellum are also activated. Somatosensory cortex is included in sensory-discrimination aspect of pain, for example body part, intensity of stimuli etc. Anterior cingulate cortex and anterior insula are involved in the analysis of affective-motivational aspect of pain, such as evaluation of personal distress. Insula is important in representation and integration of emotional states, while anterior cingulate cortex affects motivational and reaction response. Brain structures that also participate in the pain matrix are amygdala, hippocampus, and thalamus $[77,81,12,80,55,87,74$, $84,86,54,85,63,75]$.

Apart from the pain area, some studies were done on expressing other emotions such as disgust, fear, anxiety, anger, sadness, touch, reward, social exclusion, and shame, where this, aforementioned scientific data were confirmed $[77,81,55,84,86,54,85$, 63].

Finally, shared representations on cortical level between self and the other which are found in behavior analyzing, pain processing, emotion recognizing etc., all provide neurophysiological base for understanding empathy which manifests through automatic activation of motor or affective cortical representations.

\subsection{Awareness of self and the other}

Human consciousness is formed in the dynamic interrelation of self and the other and therefore is intersubjective in its essence. Knowledge of self paves the way for achieving knowledge of others. The person with the self-awareness capacity has the ability to be aware of their own mental state, as well as mental states of the other person, which is an important adaptive trait evolutionary speaking. Since the birth, through the infancy, and childhood, children perceive themselves in acting and perceiving their environment, and distinguish the self from the external world (self-awareness and other-awareness), which is completely developed by the age of 2 when they achieve social and cognitive competence. Preschoolers possess the capacity to represent and report their own mental state, as well as others' [12].

The described cognitive aspect of empathy is closely related to studies in theory of 
mind, ToM, and mentalizing. ToM refers to human metacognitive capacity to explain and understand mental state of the other person, including their beliefs, desires, intentions, and emotions [84, 86, 85, 63].

The self-awareness is crucial in appraisal of the other person's mental state and emotions. This capacity is important in empathy, and in maintaining the distinction between self and the other, having in mind at all times where the emotions come from, i.e., whether they belong to the other person or to the self. This includes the capacity for taking others subjective point of view through putting self in their shoes and imagining how that person feels.

The capacity of self-awareness and distinguishing self from the other person is related with interaction of several brain areas, namely ventromedial prefrontal cortex, medial prefrontal cortex, and inferior parietal cortex in the right hemisphere. Self-awareness is related with medial prefrontal cortex, anterior insula and secondary somatosensory cortex, while other-awareness is related with medial prefrontal cortex, frontopolar cortex, and posterior cingulate cortex $[81,12,80,55,63]$.

\subsection{Mental flexibility and self-regulation}

Understanding and experiencing other people's emotions does not automatically lead to empathy but must be regulated from within, which explains why empathy also includes emotion regulation processes. Empathy includes perspective taking, and it is an important part of it. Mental flexibility to adopt someone else's point of view is an effortful and controlled process. Children can take other people's point of view and that is what sets us apart from other primates and is an integral part of interpersonal commu- nication. That ability develops gradually. At an age of 1.5 years old, affective component of empathy is developed - that includes taking others perspective and recognizing their emotions. Cognitive component of empathy includes understanding of others mental state, intentions and beliefs, as well as executive functions such as attention, working memory, inhibition control, and self-regulation. These functions mature in adolescence $[81,12]$.

Emotion regulation, which Decety and Jackson $[12,80]$ included in empathy as one of its components, is defined as the process of initiating, avoiding, inhibiting, maintaining, or modulating the occurrence, form, intensity, or duration of internal emotional state, emotion-related psychological processes and goals, and behavioral concomitants of emotion, in the service of accomplishing one's goal [88]. Emotion regulation plays an important role in regulating one's own emotions so that it is not experienced as aversive, and in order for us to be able to feel positive concern for the other person. Complete empathic overflow is not what empathy's goal is. That is why emotion regulation is crucial in empathy process, especially in relationships such as physician/medical staff-patient, therapist-client, whereas one side uses empathy to help others, but thus makes them vulnerable. Due to this emotional openness and vulnerability, it is possible to become overwhelmed with emotions, experience personal distress, anxiety, aversive emotional reactions, discomfort, and negative physical excitement. In such situation, a person would no longer be able to help others. That being said, empathy needs regulation - inhibiting and suppressing of one's own sensitivity and emotional response to others pain is important in order to avoid negative interference. Regulation 
also helps maintaining right balance between resonance and understanding others suffering on the one side, and becoming emotionally overinvolved on the other [81,55].

Two brain regions play an important role in emotion regulation crucial for establishing optimal interaction between self and the other. They are orbitofrontal-ventromedial, and dorsolateral cortex which, in collaboration with subcortical regions, are involved in mediating various processes. Orbitofrontal part is in charge of emotion regulation. Ventromedial prefrontal cortex along with other regions takes part in emotion regulation (amygdala), memory (hippocampus), and executive functions (dorsolateral prefrontal cortex). Ventromedial region is a crucial component in the neural network of empathy. Anterior cingulate cortex participates in regulating both cognitive and affective processes. Neural mechanisms which regulate social perception and emotional processing are also important in understanding empathy, namely lateral and medial prefrontal cortex, medial orbitofrontal cortex, and the amygdala [81, $12,80,55]$.

\subsection{Empathy model: "bottom-up" emotion sharing processes and "top-down" emotion regulation and flexibility processes}

Decety and Lamm [55] defined empathy through three components with their neural processes, and suggested a model in which empathy consists of two processes: first, bottom-up processes of direct emotion sharing which are automatically activated, and second, top-down processes of regulation through contextual and cognitive appraisal, emotion control and regulation which lead to response flexibility making the person less dependent on external cues. This dual process describes the process of empa- thy through occurrence and development of neurophysiological processes in the person's body. Top-down processes are crucial, as they represent metacognitive feedback loop which decides whether the person reacts to others' emotional state or not. Cognitive appraisal is therefore even more important in empathy than emotional stimuli, because it may either inhibit a response to others emotional state or lead to an empathic response [55, 54, 85].

Another model similar to this one was suggested by Watt [75], and it describes the creation of empathy through four processes: first, there are the receptive processing components involved in appraisal and recognition of emotional states which includes facial expression, tones of voice and body kinetics. Then, this information reaches "global gate" that controls the relative activation of empathic state. This determinates the extent of "resonance induction" for the subject and the extent of variably degraded resonance state reflecting the other person's distress. Finally comes the activation of potential comforting behavior to ease distress of the other person, or inhibition of the response [75].

\section{Other factors related to empathy}

\subsection{Neurochemical basis of empathy}

Attachment theory provides a compelling framework for understanding the one's capacity to connect with others, and develop supportive relationships as coping resources, and predicts individual differences in empathic ability. Researches indicate that attachment security is related to empathy and also to empathic concern and caregiving $[81,75]$.

Many researches tried to reveal neuroanatomical and neurochemical foundations of attachment-related processes. Such research- 
es have shown that a number of neuropeptides are involved in attachment-related social behavior, including oxytocin, vasopressin and opioids. Oxytocin is involved in sexual behavior, child birth, lactation, affection, and maternal behavior. Besides, it plays a role in a complex social cognition and behavior including pair bonding, attachment, trust, generosity, empathy, empathic concern, empathic accuracy, fear and aggression, as well as perception of our and others emotional states, perceived social connectedness and support or social-evaluated threat. It can be viewed as biological sensitivity to social context. Studies show that oxytocin increase empathy and prosocial behavior [81, 63]. Vasopressin is related to many forms of social behaviours, including protective aggression, anxiety, pair bonding in a man, social communication and recognition, as well as perception of emotional faces or situations in man. It increases affiliate behavior in women [74]. Opioids also have significant role in social behavior and attachment. Endogene opioids are released during social contact and this cause rewarding feeling of attachment. On the contrary, exogenous opioids have the opposite effect, in reducing the need for attachment. Patients with opioid addiction show reduced empathic concern. Studies also discuss potential role of other neurotransmitters such as dopamine and serotonin in mediating our ability to social cognition, which means they are also related to empathy [74]. It seems that variety of neurochemical compounds participate in the formation and modulation of empathy.

Many twin studies, genetic association studies and imaging genetics have shown the evidence for genetic contribution explaining individual differences in empathy. Metaanalysis has shown genetic factors accounted for $35 \%$ of the variance of empathy in gen- eral. Researchers also isolated specific genes which are contributing to heritability of empathy $[74,63,75]$. Certain metabolic states reduce empathic response, such as hunger, fatigue, sleep deprivation, and pain [75].

\subsection{Contextual and personality factors modulating empathy}

Different contextual factors, personality traits of the observed person and social behavior affect the observer's formation of empathic response. Familiarity and relatedness as well as competition and envy play an important role in empathy. Factors that were found in research to be positive related to empathy are: positive relationship between observer and the other person, level of mutual closeness (siblings, caregivers, best friends) and similarity (personal attributes, biological and social background), belonging to the same group (sports team, race, religion), assessment of others fair play (variety of games), assessment of others helplessness, assessment of others emotional state (aggression and negative emotions of the other person inhibit the observer's empathy in opposite to pain and suffering), social comparison (evaluation of others social status, resources, success) $[77,74,78,54,75]$.

\subsection{Psychopathology and empathy deficits}

Medical practice and research, especially in neurology and psychiatry, have shown that in certain psychological and brain pathology empathy is reduced and show deficits. This also occurred in researching damages of particular regions in the brain related to different empathy processes, whereas lack of certain empathy components is related to damages in specific brain area. Generally, low empathy is usually connected to damage in the fron- 
tal, i.e. prefrontal cortex, especially to right hemispheric lesions. Besides, childhood experience has certain impact to biological development of a person. Studies show if the person was not exposed to enough affection and empathic exchange in parent-child relationship and did not develop empathic skills accordingly, it can lead to maladaptive neurological development of the child and later be the cause of reduced capacity for empathy. Psychopatological conditions which are accompanied with empathy deficits are: autism, Asperger syndrome, ADHD, alexithymia, conduct disorder, psychopathy, antisocial, narcissistic and borderline personality disorder, as well as other personality disorders, schizophrenia, bipolar disorder, Parkinson's disease, dementia (frontotemporal, semantic), Huntington's disease $[77,81,12,74,84$, 75].

\section{Measuring empathy}

The measurement of empathy is a serious challenge for researchers in many disciplines from social psychology, individual differences, and clinical psychology. Part of this challenge is due to the lack of a clear, universal definition for empathy. However, contemporary definitions are more complex and highlight a range of cognitive, affective, and physiological processes. From 1940s until today, researches used various approaches to measure empathy [89]. Empathy research pioneers, Cottrell and Dymond [90], proved that it was possible to develop a quantitative index of empathic ability. Reliability and validity of the measure presented by them could not be viewed as the final results, but it was good enough to claim that the improvement of their measure or similar one would lead to valid and reliable empathy measure [90].
Empathy measures were significantly influenced by cognitive approach due to cognitive psychology's popularity throughout $20^{\text {th }}$ century (Diplomacy Test of Empathic Ability [91]; Empathy Scale [91]), even though important measures were also emotion-based (Emotional Empathic Tendency; [92]). In 1980s and 1990s, social and developmental psychology emphasized the multidimensionality of the empathy emphasizing physiologically linked affective states [93], cognitive processing, or a self-awareness of these feelings [93], and emotion regulation [94, 95]. Since 1990s, empathy measures have been influenced by the development of socio-cognitive neuroscience, although self-report approaches have continued to be developed and extensively used [89].

Hall and Schwartz [47] found that 78\% of 393 empathy-related scientific studies published between 2001 and 2013 used one or more empathy measures: $80 \%$ of the instruments measured self-reported empathy, $12 \%$ measured empathy rated by someone else, and 7\% measured rating of someone else's empathy. Total sum included 72 used measures. Most common measured aspects of empathy were: perspective taking (22\%), fantasy $(15 \%)$, empathic concern $(30 \%)$, and personal distress $(12 \%)$.

There is the great diversity in approaches to measuring empathy which reflect the highly complex and multifaceted nature of empathy. Measures can be grouped into three major categories: 1. Self-report instruments, 2. Behavioral observational methods, and 3. Neuroscientific approaches [89].

First category of empathy measures, subjective self-report measures of empathy currently provide the most comprehensive measures to date and are most common in scientific studies. They include paper-and- 
pencil measures. For the purposes of this paper we shall present four scales: one of the first self-report empathy measure, Hogan's Empathy Scale [9]; two most commonly used measures, Interpersonal Reactivity Index, and Empatby Quotient [47], as well as E-Questionnaire: Emotional Empatby Scale and Fantasy Scale [60] which is an example of self-report empathy measure developed in Croatia. There are other self-report empathy measures that are also important: Balanced Emotional Empathy Scale [96], Multidimensional Emotional Empathy Scale [97], Feeling and Thinking Scale [98], Basic Empatby Scale [99], Griffith Empathy Measure [100], Toronto Empathy Questionnaire [101] and Questionnaire of Cognitive and Affective Empatby [102], which are also widely used [47].

\section{Empathy Scale}

Hogan's Empathy Scale, HES [9] is historically very important measure as a one of the first self-report empathy measure and as an empirically keyed empathy scale. Hogan constructed Empathy Scale within framework of multidimensional theory of moral development. He has suggested that moral development can be conceptualized and moral conduct explained in terms of five dimensions (moral knowledge, socialization, empathy, autonomy, and a dimension of moral judgment), each defined by a separate measure [103, 104]. Empathy, seen as an everyday manifestation of the disposition to adopt a broad moral perspective, to take "the moral point of view," also becomes important within the context to research in moral development [9]. HES may be considered as a more cognitive measure of empathy developed from the definition that empathy is "the intellectual or imaginative apprehension of another's condition or state of mind without actually experiencing that person's feelings" [9].
The empathy scale was developed by the standard technique of an items analysis the responses of high-rated versus low-rated groups, and were compared with 957 truefalse items in the California Psychological Inventory (CPI), the Minnesota Multiphasic Personality Inventory (MMPI), and a University of California's Institute of Personality Assessment and Research (IPAR) pool of items. From these analyses, 64 items (32 scored true, 32 false) were selected for the final scale, of which 31 items are taken from CPI, 25 from MMPI, and the remaining 8 from various experimental studies of IPAR [9].

HES sample items: As a rule I have little difficult time putting myself into other people's shoes; I have seen some things so sad that I almost felt like crying; I have a pretty clear idea of what I would try to impart to my students if I were a teacher, I frequently undertake more than I can accomplish [9]. According to Hogan [9], empathy is predicative of low anxiety, self-acceptance, lack of authoritarian tendencies, and extroversion. Johnson, Cheek and Smither [105] listed various studies by other authors, and claim that Hogan's Empathy Scale is a reliable empathy measure. In correlation with other measures and by psychometric analysis, they conclude that Empathy Scale can be defined by four scales: Social Self-Confidence, Even Temperedness, Sensitivity, and Non-conformity. However, same authors argued questionable psychometric properties of Hogan's scale based on their own research.

\section{Interpersonal reactivity index}

Davis' Interpersonal reactivity index, IRI [105], though constructed in 1980, is by far the most widely and frequently used empathy measure until today [47]. Its popularity is attributable to several desirable qualities. 
First, this scale is the only one that is based on a multidimensional conceptualization of empathy. Second, the IRI is regarded as the most comprehensive measure of self-reported empathic dispositions. Finally, this scale is relatively short and thus simple to administer [106].

The IRI consist of 38 items and four scales, each measuring a distinct component of empathy: perspective taking (P'), empathic concern (EC), fantasy (FS), and personal distress (PD). The PT scale measures the process of role taking, the tendency to adopt the psychological points of view of others. PT sample items: I believe that there are two sides to every question and try to look at them both; Before criticizing somebody, I try to imagine how I would feel if I were in their place. The EC scale measures the affective outcomes, the tendency to experience other-oriented feelings and the response to distress in others with the reactive response of sympathy and compassion. EC sample items: I am often quite touched by things that I see happen; When I see someone being taken advantage of, I feel kind of protective toward them). The FS scale measures the tendency to transpose oneself into feelings and actions of fictitious characters. FS sample items: When I am reading an interesting story or novel, I imagine how I would feel if the events in the story were happening to me; When I watch a good movie, I can very easily put myself in the place of a leading character. The PD scale demonstrates an affective outcome, and is designed to tap ones' own feelings of personal unease and discomfort in reaction to the emotions of others. PD sample items: I sometimes feel helpless when I am in the middle of a very emotional situation; I tend to lose control during emergencies [107, 105, 108]. The PD, EC and FS scales assess affective components of empathy, whereas the PT scale represents the cognitive component.
A number of studies have shown that the IRI provides a reliable and valid way of measuring people's empathic tendencies via self-report [108]. However, there is still some need to further investigate certain validity issues.

\section{Empathy Quotient}

Empathy quotient, EQ created by BaronCohen and Wheelwright [66] is the second most commonly used measure in the period between 2001 and 2013 [47]. Authors defined empathy as "the drive to identify another person's emotions and thoughts, and to respond to these with an appropriate emotion" [66]. EQ was designed to be a short, easy to use scale that measures both cognitive and affective components of empathy. It contains 40 empathy items and 20 control items included to provide some distraction and to minimize the focus on empathy. Empathy sample items: I can easily tell if someone else wants to enter a conversation; I find it difficult to explain to others things that I understand easily, when they don't understand it first time; Friendships and relationships are just too difficult; I really enjoy caring for other people. Control sample items: I dream most nights; I am at my best first thing in the morning; I would never break a law, no matter how minor; I would be too nervous to go on a big rollercoaster [66].

\section{E-questionnaire}

E-questionnaire was created by RabotegŠarić [60]. The author was aware of the complexity of the empathy concept, and conducted a study in which was constructed a new empathy measure that is appropriate for adolescents and context of our country. Having in mind preliminary research done on students in the final version of e-questionnaire, 
the author kept two scales measuring different aspects of empathic experience: Affective empathy scale, and Fantasy scale. Affective empathy scale measures the affective reaction to other person's emotional state, as well as care, sympathy and affective arousal for the other person in difficult situation. It consists of 19 items which measure global affective empathy reaction. Affective empathy sample items: I get sad when I see helpless people; I feel bad if I have to be the bearer of bad news. Fantasy scale measures ability to imagine emotions and actions of characters in stories, novels, and movies. Fantasy sample items: When I am watching a movie, I imagine being one of the characters on screen; When I am watching a good movie, I am so taken in that I do not see or hear anything around me [60].

In the second category of empathy measures are behavioral observational methods such as Picture Viewing Paradigms [109], Comic Strip Task [110], Picture Stories [111], and Kids Empathetic Development Scale [112]. These methods include evaluations of experimental stimuli and performance on tests. For example, participants are watching images (static images or video clips) depicting individuals who are in certain situations, often negative (confinement, injury, grief), but they may also be positive, and make a rating response to what degree are able to imagine feeling and experiencing what the other one is experiencing; participants are given a series of comic strips and have to choose the best one out of two or three strips on an answer card to finish the story; participants have to interpret visual scenes (aversive and neutral) in color pictures, and predict the most likely behavioral consequence based on cognitive or affective cues [89].

The third category of empathy measures is a neuroscientific approach to empathy which includes various medical techniques used in neuroscience studies, such as brain imaging techniques (fMRI) and other measures of central nervous system activity (electroencephalography, EEG), measure of facial electromyography (EMG), and autonomic nervous system measures (skin conductance, heart rate), which are all used to confirm neural correlates and basis of empathy. Neuroscienfitic measures are highly important for future research of empathy [89].

The great diversity in approaches to measuring empathy could mean that researchers have yet to find an adequately reliable and valid measure of empathy, there is highly complex and multifaceted nature of empathy, and what empathy is and how it should be measured is different from situation to situation or population to population. Uncertainty remains as to whether empathy should be measured as a one-dimensional or a multidimensional construct measuring one or more components. Some limitations of self-report measures are subjectivity and susceptibility to motivational distortion, response bias (social desirability of empathy), and that each measure has been based on a different definition of empathy. On the other hand, neuroscientific measures of empathy are expanding field in future research. A potentially promising is to combine measures to provide a comprehensive approach to empathy assessment. The studies using one or more measures show that they have high inter-correlation [96].

\section{Empathy training}

Empathy training has been an ongoing topic of discussion and an area of research since the 1960s. Developing the ability to perceive and understand other people's emo- 
tions and cognitions has deep roots in developmental psychology. Empathy is one of the primary skills for interpersonal communication and relationships, and like other skills, can develop in various ways and be trained. It can be taught through good examples of empathic behavior in key figures during childhood, in education, initiation in society, etc. It is important to encourage the development of empathic skills because empathic person positively affects both others' and their own psychological-physical-social health.

Many studies discuss the possibility of learning and developing empathy ability through training or enhancement programs. Researchers have attempted to teach individuals the meaning of empathy, to recognize emotions in others, to take the perspective of others, and to show empathy in various social situations. Many empathy training program studies have tried to increase empathy levels in different helping professions such as physicians, therapists, medical students, and nurses. A popular area for empathy training is for children and adolescents, and also for psychiatric patients and criminal offenders [113]. Empathy training is very useful in educational context for children and teachers, it can increase tolerance, academic achievement, emotional intelligence, and pro-social behavior, improve communication skills, and on the other hand, it can decrease problems of social prejudice and aggression among children [27]. When it comes to health, empathic communication skills are associated with increased patient satisfaction, improved adherence to therapy, decreased medical errors, fewer malpractice claims, better health outcomes, decreased burn-out and increased physical wellbeing [114].

Three types of empathy could be targeted in training: cognitive, affective, and behav- ioral. Empathy training programs employ a number of methods included experiential training (instructors provide "experiences" such as games and role-play), didactic (lecture based), skills training (lectures, demonstrations, and practice), and mixed methods. Many of these correspond to methods found in behavioral skills training, which includes modeling, instructions, rehearsal, and feedback. Some reviews of interpersonal skills training, including empathy training, have suggested a training length of 1-3 days [113].

Training methods can be classified into seven types: 1 . experiential training - emphasizes gaining experience on the part of the trainees to be a critical factor in meaningful learning. The instructors are facilitators who design experiences for trainees; 2 . didactic and experiential training - the facilitator lectures on theory and concepts and then provides experiences for the participants through games, internships, live cases, problem solving, and so on; 3. skill training - consists of three components: provide trainees with a description of well-defined skills to be learned, demonstrate the effective use of these skills through modeling, and provide practice opportunities using these skills; 4. didactic and skill training; 5. mindfulness training - involves teaching trainees to become mindful, i.e., to be in a state of non-judgmental awareness grounded in the present moment; 6 . video stimulus training - the trainer asks the participants to watch a videotape about others' empathic behaviors, or their own, in mock situations, and to respond to the videotaped excerpts during the viewing or afterwards. The training session could also be followed by discussion and feedback, and 7 . writing training - a training method that entails asking trainees to write from the other's point of view or perspective [115]. Some research has divided the tech- 
niques used in empathy training into similar four major categories: didactic, experiential, role-playing and modeling. Additionally, the important role have social promotions, taking initiations, affective support from the social environment, reinforcement and ethical judgments in developing empathic attitudes among children [116].

Teding van Berkhout and Malouff [113] using a meta-analysis examined the effects of empathy training in 19 studies. The overall effect size of the all 19 studies was significant, supporting the hypothesis that empathy training would be efficacious. Authors cited that studies have demonstrated that psychotherapist empathy is an important feature of successful treatment by psychologists [117], social workers [116], and substance abuse counselors [119]. Studies have also found that empathy is associated with better patient outcomes for physicians [114,120] and increased patient adherence to treatments [121]. In nonprofessionals, research results have indicated that high levels of empathy are associated with enhanced personal relationships [122] and prosocial behavior [123]. Conversely, studies have shown that a lack of empathy is associated with negative outcomes, including aggressive behavior such as bullying and sexual offending [124, 99, 125].

Chiu Ming Lam, Kolomitro and Alamparambil [115] using narrative review method analyzed 26 quantitative and 3 qualitative studies of empathy training. Findings suggest that regardless of the training method, individuals can learn about the concept of empathy. Unfortunately, information pertaining to the effects of training on individuals' empathy is lacking. Data from the studies reviewed were neither complete nor valid enough to provide a clear and full understanding of the trainability of empathy. More research is needed in designing future studies.
Studies show importance in determining the critical period during human development which indicated when it is the best to teach socially relevant skills as empathy. Such findings would be useful in achieving successful education through activating one's own welfare, efficient emotion regulation, meaningful interpersonal relationships, prosocial motivation and behavior in general, and development of resilience which then lead to better coping with stressful situations. Despite psychological findings about possibility of transforming social emotions through training, neuroscience is paying a great attention to neuroplasticity of the human brain, which is considered one of the greatest scientific breakthroughs. It could be used as background information for developing and learning how to be empathic and could lead to further research to investigate the neural plasticity underlying capacity for empathy [78].

\section{The other side of empathy}

Most of the studies state that empathy is a desirable trait and social characteristic, but it is important to emphasize that some authors do not share that opinion entirely, giving evidence for negative behaviour that results from empathy. They problematize epistemological contribution to empathy [126], they question the possibility of knowing other person's emotions, and claim that empathic knowledge is inconceivable and morally problematic $[127,128]$, as well as expressing concerns about the power of fake empathy which can cause damage to interpersonal and social relationships [129].

Bubandt and Willerslev [130] state (we should) "while the renewed interest in empathy promises a fresh look at the conditions 
of possibility of sociality itself, we argue that this potential can only be realized if we give up the implicit idea that empathy is always a moral virtue and instead embrace a broader approach that also encompasses its darker, but no less social side quite frequently, empathic identifications with others do not have as their goal mutual understanding, altruism, consolation, intersubjective compassion, care, or social cohesion - goals conventionally regarded as the sine qua non of empathy. Instead, the empathic faculty is used for deceptive and ultimately violent purposes". In situations like that, motivation for empathic actions may be seduction, fraud, manipulation, or wild tendencies, called "tactical empathy" [130].

Using the term "spotlight vision", Prinz [131] and Bloom [127] describes empathy as a means of focusing attention for a short time on an individual fate while neglecting the larger picture, long-term solutions, and large numbers of people. Spotlight effect of empathy explains how empathy can be a powerful trigger of behaviour since it draws one's awareness to one scene or person. However, it also explains how empathy can be manipulated. People are willing to donate time and money to one hungry child but not be moved by the fate of thousands suffering from famine or war.

The "polarizing effect of empathy" is connected to the previous point. In general, when someone is empathizing with others, he can agree with their opinions, share their emotions, and adopt their viewpoints. In situations of conflict, one may support the side he have felt empathy for, while neglecting the other side. If the empathizer adopts some of the preferences of the person of his empathy, it is likely that aversions towards the other side are also adopted. These can lead to people committing aggressive acts against the other side of a conflict and of side-taking and empathy can help to revise understandings of some hateful acts [64].

An empathic person can draw out many positive effects for themselves while being empathetic toward someone who is suffering and it can be seen as "selfish empathy". It can arouse positive emotions which play a strong role in life satisfaction, it can enriches one's range of experience by expanding the perception of a person beyond his or her own senses and immediate situations, it allows people to participate in the lives of others or situations other than their current situation. However, current researchers do not have a clear picture on all mechanisms of that type of empathy so far [64].

One of the forms of the selfishness of empathy is so-called "empathic vampirism", through which other person becomes a medium of one's own experience. The empathizer feels and experiences the world vicariously via others and thereby participates in their fate, without, however, having their best interests in mind. It consists of the process of sharing another's experience and making it one's own over time, without concern for the other's long-term welfare as an independent being. The force of this definition lies in the idea of making it your own, of appropriating it. Stalkers, fans, stage parents, and helicopter parents fall under this definition of using others as medium of their experience [64]. One of the prime examples for this phenomenon is "belicopter parenting", in which parents' interest lies in experiencing a perfect youth retrospectively via their children - more perfect, at least, than their own [132].

"Empathic sadism" or "empathic cruelty" is another form of selfish empathy which in its basic form, means that an empathic observ- 
er enjoys the pain or suffering of other person [133]. The negative feelings of other are translated by the empathizer into their positive ones. It can appear in a variety of forms such as enjoyment of tragedies and sad movies [134], as a motivation for punishment [133], in sadistic acts, in schadenfreude, and in everyday behaviours like bullying, shaming, and teasing. Sadistic empathy often includes the manipulation of others and can be understood as bringing about a situation for the other with the goal of making their emotional response to that situation intelligible, and therefore possible to share. Psychopaths fall into the description of sadistic empathy [64].

Situations of humanitarian aid extend support to help other people beyond the simple borders of one's life, and empathy is the motivator for this behavior, as well as morality or religion, but also identification with the (real or imaginary) helper. It is called "bumanitarian empathy - filtered empatby" [64]. It is a process in which the observer in humanitarian aids identifies with the helpers, believing they are doing something heroic, and getting a sense of pleasure in "helping", while they are merely a bystander, inactive in the pro-social behavior [135].

Taking into consideration the other side of empathy gives us possibility to expand our view on complexity and importance of the phenomena, and a motivation for developing further research in this area.

\section{Future empirical issues}

In this final section of the paper, it's important to highlight domains and questions which should be the focus of future research efforts. Some authors gave a detailed analysis of empathy research, and they critically reviewed used methodology. They suggest- ed some improvements in methodology of research which they find necessary due to complexity of the process of empathy that includes parallel and mutually intertwined psychological and biological processes. These processes do not need to be separately studied as it happened to be the case in some of the studies. Some of the suggestions regarding further research are analysis of empathy in more natural environment (less artificial and less controlled than the ones in scientific research so far, but compliant with scientific methodology), development of better models of correlation between neurological and behavioral data $[84,136]$.

It is very important to identify and analyze more precisely and systematically the variety of cultural frameworks, social situations, and political-economic conditions which either suppress and inhibit basic empathy or amplify it. Also, the basic definitions of empathy are relatively imprecise and arbitrary, and likely biased towards forms of empathy as expressed in European and North American contexts [70]. There are some problematic nature of conceptual and operational definitions in scientific studies, and therefore suggested that empathy be studied as an ability. It is important distinguishing one's own feelings from those of others, investigating how the different "empathies" relate to each other, distinguishing systematically between verbal and nonverbal empathy, establishing common categorizations and definitions, etc. [47].

Due to complexity of empathy and its multidisciplinary field of study it is important in future study to give an integrative functional model of empathy and more careful conceptualization of the phenomenon. It is also important to further explore gender differences in empathy, and differences between 
people in general, and how it change across the life span, as well as neuroscience basis and mechanisms underlying these differences. One of the special interest is understanding what motivates people to feel empathy and caring for the other because it is not automatically triggered, how empathy is linked to prosocial behavior, is it a trait or situationspecific state variable, and analysis of empathy in positive emotions (joy, pride, elation). Insights into plasticity of the brain networks underlying empathy can be gained from further clinical and neuroscience research. Very important question is how we can train people to be more empathic and which processing level (bottom-up or top-down) should be targeted and at what age should the training take place. It is necessary to have large-scale longitudinal studies which could have enormous implications for education and society as a whole $[77,12,54]$.

\section{Conclusion}

Empathy is the basis of successful interpersonal relationships, and it is an ability of establishing an acknowledging, stimulating, inspiring and flexible relationship with another person, while at the same time the empathic person contributes to their own welfare. The concept of empathy has developed

\section{References}

1. Duan C, Hill EC. The Current State of Empathy Research. J Couns Psychol. 1996;43:261-274.

2. Titchener EB. Lectures on the experimental psychology of the thought-processes. New York: Macmillan; 1909.

3. Titchener E. A textbook of psychology. New York: Macmillan; 1924. through the past century, along with disciplines such as psychology, philosophy, medicine, and neuroscience, which makes it very significant for the welfare of both individuals and society. Different studies pointed out different concepts of empathy and its definition, either affective or cognitive empathy, but integrating both components is crucial for understanding empathy as a whole. Some uncertainties are still present in understanding of the phenomenon, and empathy overlaps with some aspects of other similar phenomena like emotional contagion, sympathy and compassion. Developing positive attitude toward empathy and through its training it can contribute to healthier interpersonal relationships and increase prosocial behavior in society, while its negative aspects should be observed in certain context. Further research in the field of empathy as one of the most vital and flexible human ability will continue to explore and develop in greater detail this very important phenomenon.

\section{Acknowledgement}

None

\section{Conflict of Interest}

None to declare
4. Rolbin C, Della Chiesa B. "We Share the Same Biology..."Cultivating Cross-Cultural Empathy and Global Ethics Through Multilingualism. Mind Brain Educ. 2010;4:196-207.

5. Husserl E. Phänomenoligische Psychologie. The Hague: Martinus Nijhoff; 1962. p. 321.

6. Stein E. On the problem of empathy. The Hague: Martinus Nijhoff; 1912/1964. 
7. Stein E. Zum Problem der Einfühlung. Edith Stein Gesamtausgabe 5. Freiburg: Herder; 2008.

8. Mead GH. Mind, self, and society. Chicago: University of Chicago Press; 1934.

9. Hogan R. Development of an Empathy Scale. J Consult Clin Psychol. 1969;33:307-316.

10. Kohut H. The restoration of the self. New York: International Universities Press; 1977.

11. Freud S. Group psychology and the analysis of the ego. London: Hogarth; 1921.

12. Decety J, Jackson PL. The functional architecture of human empathy. Behav Cogn Neurosci Rev. 2004;3:71-100.

13. Fenichel O. The psychoanalytic theory of neurosis. New York: Norton; 1945.

14. Decety J. Dissecting the Neural Mechanisms Mediating Empathy. Emot Rev. 2011;3:92-108.

15. Kohut H. On Empathy. Int J Psychoanal Self Psychol. 2010;2:122-131.

16. Kohut H. The analysis of the self: A Systematic Approach to the Psychoanalytic Treatment of Narcissistic Personality Disorder. New York: International Universities Press; 1971.

17. Beres D, Arlow JA. Fantasy and identification in empathy. Psychoanal Q. 1974;43:26-50.

18. Basch MF. Empathic understanding: A review of the concept and some theoretical considerations. J Am Psychoanal Assoc. 1983;31:101-126.

19. Rogers C. The attitude orientation of the counselor. J Consult Psychol. 1949;13:82-94.

20. Rogers C. Client-centered therapy. Boston: Houghton Mifflin; 1951.

21. Rogers C. The necessary and sufficient conditions of therapeutic personality change. J Consult Psychol. 1957;21:95-103.

22. Rogers C. A theory of therapy, personality and interpersonal relationships as developed in the client-centered framework. In: Koch S, ed. Psychology: A study of a science. Study 1. Conceptual and systematic: Vol. 3. Formulations of the person and the social context New York: McGraw-Hill. 1959; p. 184-256.

23. Book HE. Empathy: Misconceptions and misuses in psychotherapy. Am J Psychiatry. 1988;145:420424.

24. Buie DH. Empathy: Its nature and limitations. J Am Psychoanal Assoc. 1981;29:281-307.
25. Danish SJ, Kagan N. Measurement of affective sensitivity: Toward a valid measure of interpersonal perception. J Couns Psychol. 1971;18:51-54.

26. Easser BR. Empathic inhibition and psychoanalytic technique. Psychoanal Q. 1974;43:557-580.

27. Feshbach ND, Feshbach S. Empathy and education. In: J. Decety J, W. Ickes W, ed. Social neuroscience. The social neuroscience of empathy. Cambridge: MIT Press. 2009. p. 85-97

28. Hoffman ML. Development of prosocial motivation: Empathy and guilt. In N. Eisenberg eds. The development of prosocial behavior. New York: Academic Press. 1982. p. 281-313.

29. Hoffman ML. Interaction of affect and cognition in empathy. In Izard CE, Kagan J, Zajonc RB. eds. Emotion, cognition, and behavior. Cambridge: Cambridge University Press. 1984. p.103-131.

30. Kerr WA. The empathy test. Chicago: Psychometric Affiliates. 1947.

31. Iannotti RJ. The nature and measurement of empathy in children. Couns Psychol. 1975;5:21-25.

32. Davis MH. Measuring Individual Differences in Empathy: Evidence for a Multimodal Approach. J Pers Soc Psychol. 1983;44:113-126.

33. Barrett-Lennard GT. The phases and focus of empathy. Br J Med Psychol. 1993;66:3-14.

34. Greenson RR. Empathy and its vicissitudes. Int J Psychoanal. 1960;41:418-424.

35. Greenson RR. The technique and practice of psychoanalysis (Vol. 1). New York: International Universities Press. 1967.

36. Batson CD, Darley JM, Coke JS. Altruism and human kindness: Internal and external determinants of helping behavior. In: Pervin L, M. Lewis M, ed. Perspectives in interactional psychology. New York: Plenum Press; 1978

37. Katz TF. Activities of Daily Living. AMA. 1963;185:914-919.

38. Stotland E. Exploratory Investigations on Empathy. Adv Exp Soc Psychol. 1969;4:271-314.

39. Truax CB, Carkhuff RR. Toward effective counseling and psychotherapy: Training and practice. Chicago: Aldine; 1967.

40. Feshbach ND, Roe K. Empathy in six- and sevenyear-olds. Child Dev Res. 1968;39:133-145.

41. Carkhuff RR. Helper communication as a function of helpee affect and content. J Couns Psychol. 1969;16:126-131. 
42. Emery EJ. Empathy: Psychoanalytic and client centered. Am Psychol. 1987;42:513-515.

43. Reik T. Listening with the third ear: the inner experience of a psychoanalyst. Oxford: Farrar, Straus \& Co; 1948.

44. Rogers C. Empathic: An Unappreciated Way of Being. The Counseling Psychologist. 1975;5:2-10.

45. Kohut H. Introspection, empathy, and the semicircle of mental health. In: Lichtenberg J, Bornstein M, Silver D, ed. Empathy I. Hillsdale, NJ: The Analytic Press; 1984. p. 81-100.

46. Gladstein GA. Understanding empathy: Integrating counseling, developmental, and social psychology perspectives. J Couns Psychol. 1983;30:467-482.

47. Hall AJ, Schwartz R. Empathy present and future. The Journal of Social Psychology. [Internet]. 2018 [cited 15 August 2018]. Available from: https:// www.tandfonline.com/doi/full/10.1080/0022454 5.2018 .1477442

48. Barrett-Lennard GT. The empathy cycle: Refinement of a nuclear concept. J Counseling Psych. 1981;28:91-100.

49. Archer RL, Diaz-Loving R, Gollwitzer PM, Davis $\mathrm{MH}$, Foushee HC. The role of dispositional empathy and social evaluation in the empathic mediation of helping. Pers Soc Psychol Rev. 1981;40:786796.

50. Riess H. The Impact of clinical empathy on patiens and clinicians: Understanding empathy's side effect. AJOB Neurosci. 2015;6:51-53.

51. Shamay-Tsoory SG, Aharon-Peretz J, Perry D. Characterization of empathy deficits following prefrontal brain damage: the role of the right ventromedial prefrontal cortex. J Cogn Neurosci. 2009;15:324-337.

52. Mercer SW, Maxwell M, Heaney D, Watt GC. The consultation and relational empathy (CARE) measure: development and preliminary validation and reliability of an empathy-based consultation process measure. Family Practice. 2004;21:699-705

53. Bartky S. "Sympathy and Solidarity: On a Tightrope with Scheler." In: Meyers DT, ed. Reminists Rethink the Self. Oxford: Westview Press; 1997. p. 177-196.

54. Singer T, Lamm C. The Social Neuroscience of Empathy. The Year in Cognitive Neuroscience. 2009;1156:81-96.
55. Decety J, Lamm C. Human empathy through the lens of social neuroscience. Sci World J. 2006;6:1146-1163.

56. Lamm C, Rütgen M., Wagner IC. Imaging Empathy and Prosocial Emotions. Neuroscience Letters. [Internet]. 2017 [cited 15 August 2018]. Available from:https://www.researchgate.net/ publication/324811636_The_neuroscience_of empathy_-_from_past_to_present_and_future

57. Batson CD. These things called empathy: eight related but distinct phenomena. In: J. Decety J, Ickes W, ed. The Social Neuroscience of Empathy. Cambridge: MIT Press; 2009. p. 3-15.

58. Hein G., Singer T. I feel how you feel but not always: The empathic brain and its modulation. Curr Opin Neurobiol. 2008;18:153-158.

59. Watt D. Toward a Neuroscience of Empathy: Integrating Affective and Cognitive Perspectives. Neuropsychoanalysis 2014;9:119-140.

60. Raboteg-Šarić Z. Empatija, moralno rasuđivanje i različiti oblici prosocijalnog ponašanja. [disertacija]. Zagreb: Filozofski fakultet Sveučilišta u Zagrebu; 1993.

61. Rozin P, Royzman EB. Negativitiy bias, negativity dominance, and contagion. Personality and Social Psychology Review. 2001;5:296-320.

62. Light SN, Coan JA, Zahn-Waxler C, Frye C, Goldsmith HH, Davidson RJ. Empathy is associated with dynamic change in prefrontal brain electrical activity during positive emotion in children. Child Dev. 2009;80:1210-1231.

63. Walter H. Social cognitive neuroscience of empathy: Concepts, circuits, and genes. Emot Rev. 2012;4:9-17.

64. Breithaupt F. The bad things we do because of empathy. Interdiscip Sci Rev. 2018;43:166-174.

65. Wispé L. The distinction between sympathy and empathy: To call forth a concept, a word is needed. J Pers Soc Psychol. 1986;50:314-321.

66. Baron-Cohen S, Wheelwright $S$. The empathy quotient: an investigation of adults with Asperger syndrome or high functioning autism, and normal sex differences. J Autism Dev Disord. 2004;34:163175.

67. Cuff BMP, Brown SJ, Taylor L, Howat DJ. Empathy: A review of the concept. Emot Rev. 2016;8:144153.

Alcoholism and Psychiatry Research 2018;54:123-150 
68. Roskies AL. A Puzzle about Empathy. Emot Rev. 2011;3:278-280.

69. Strayer J. Affective and cognitive processes in empathy. In: Eisenberg N, Strayer J, ed. Empathy and its development. New York: Cambridge University Press; 1987. p. 218-244.

70. Hollan D. Emerging Issues in the Cross-Cultural Study of Empathy. Emot Rev. 2012;4:70-78.

71. Oliveira-Silva P, Gonçalves OF. Responding empathically: A question of heart, not a question of skin. Appl Psychophysiol Biofeedback. 2011;36:201-207.

72. Barker RL. The social work dictionary. Washington, DC: NASW Press; 2008.

73. Hatfield E, Cacioppo JT, Rapson RL. Emotional Contagion. Cambridge; Cambridge University Press; 1994.

74. Gonzalez-Liencres C, Shamay-Tsoory S, Brüne M. Toward a neuroscience of empathy: Ontogeny, phylogeny, brain mechanisms, context and psychopathology. Neurosci Biobehav Rev. 2013;37:15371548.

75. Watt D. Toward a Neuroscience of Empathy: Integrating Affective and Cognitive Perspectives. Neuropsychoanalysis 2007; 9:119-140.

76. Hatfield E, Rapson RL, Le, Y. L. Emotional contagion and empathy. In: Decety J, Ickes JW, ed. The Social Neuroscience of Empathy. Cambridge, MA: MIT; 2009.

77. Bernhardt BC, Singer T. The Neural Basic of Empathy. Annu Rev Neurosci. 2012;35:1-23.

78. Singer T, Kimecki OM. Empathy and compassion. Curr Biol. 2014;24:875-878.

79. Eisenberg N. Emotion, regulation, and moral development. Annu Rev Psychol. 2000;51:665-697.

80. Decety J, Jackson PL. A Social-Neuroscience Perspective on Empathy. Curr Dir Psychol Sci. 2006;15:54-58.

81. Decety J. Dissecting the Neural Mechanisms Mediating Empathy. Emot Rev. 2011;3:92-108.

82. Preston SD, de Waal FBM. Empathy: Its ultimate and proximate bases. Behav Brain Sci. 2002;25:1-72.

83. Gallesse V, Fadiga I, Fogassi L, Rizzolatti G. Action recognition in the premotor cortex. Brain. 1996;119:593-609.

84. Rameson LT, Lieberman MD. Empathy: a Social Cognitive Neuroscience Approach. Soc Personal Psychol Compass. 2009;3:94-110.
85. Trapp S, Schütz-Bosbach S, Bar M. Empathy: The Role of Expectations. Emot Rev. 2018;10:161-166.

86. Singer T. The neuronal basis and ontogeny of empathy and mind reading: Review of literature and implications for future research. Neurosci Biobehav Rev. 2006;30:855-863.

87. Decety J, Smith KE, Norman GJ, Halperm J. A social neuroscience perspective on clinical empathy. World Psychiatry. 2014:13:233-237.

88. Eisenberg N, Smith CL, Sasovsky A, Spinrad TL. Effortful control. In: Baumeister RF, Vohs KD, ed. Handbook of Self-Regulation. New Yorl: The Guilforg Press; 2004. p. 259-282.

89. Neumann D, Chan RCK, Boyle GJ, Wang Y, Wesstbury HR. Measures of Empathy: Self-Report, Behavioral and Neuroscientific Approaches, In: Boyle GJ, Saklofske DH, Matthews G, ed. Measures of Personality and Social Psychological Constructs. London: Elsevier; 2015. p. 258-289.

90. Cottrell LS, Dymond RA. The empathic responses: A neglected field of research. Psychiatry. 1949;12:355-359.

91. Kerr WA. Diplomacy Test of Empathy. Chicago: Psychometric Affiliates; 1960.

92. Mehrabian A, Epstein N. A measure of emotional empathy. J Pers. 1972;40:525-543.

93. Batson CD. Self-reported ratings of empathic emotion. In: Eisenberg N, Strayer J, ed. Empathy and its development. Cambridge: Cambridge University Press; 1987.

94. Eisenberg N, Fabes RA, Murphy B, Karbon M, Maszk M, Smith M, et al. The Relations of emotionality and regulation to dispositional and situational empathy-related responding. J Pers Soc Psychol. 1994;66:776-797.

95. Gross JJ. Antecedent- and response-focused emotion regulation: divergent consequences for experience, expression, and physiology. J Pers Soc Psychol. 1998;74:224-237.

96. Mehrabian A. Manual for the Balanced Emotional Empathy Scale (BEES). Monterey, CA: Albert Mehrabian; 1996.

97. Caruso DR, Mayer JD. A Measure of Emotional Empathy for Adolescents and Adults. Unpublished Manuscript; 1998.

98. Garton AF, Gringart E. The development of a scale to measure empathy in 8- and 9-year old 
children. Australian Journal of Education and Developmental Psychology. 2005;5:17-25.

99. Jolliffe D, Farrington DP. Examining the relationship between low empathy and bullying. Aggress Behav. 2006;32:540-550.

100. Dadds MR, Hunter K, Hawes DJ, Frost ADJ, Vassallo S, Bunn P, et al. A measure of cognitive and affective empathy in children using parent ratings. Child Psychiatry Hum Dev. 2008;39:111122.

101. Spreng RN, McKinnon MC, Mar RA, Levine B. The Toronto Empathy Questionnaire: Scale development and initial validation of a factor-analytic solution to multiple empathy measures. J Pers Assess. 2009;91:62-71.

102. Reniers R, Corcoran R, Drake R, Shryane NM, Völlm BA. The QCAE: A questionnaire of cognitive and affective empathy. J Pers Assess. 2011;93:84-95.

103. Hogan R. Moral conduct and moral character: A psychological perspective. Psychol Bull. 1973;79:217-232.

104. Johnson JA, Cheek JM, Smither R. The structure of empathy. J Pers Soc Psychol. 1983;45:12991312.

105. Davis M. A multidimensional approach to individual differences in empathy. JSAS Catalog of Selected Documents in Psychology. 1980;10,85. [Internet]. 2018 [cited 20 August 2018]. Available from: https://www.uv.es/friasnav/Davis_1980. pdf.

106. De Corte K, Buysse A, Verhofstadt LL, Roeyers $\mathrm{H}$, Ponnet K, Davis MH. Measuring empathic tendencies: reliability and validity of the dutch version of the interpersonal reactivity index. Psychol Belg. 2007;47:235-260.

107. Cliffordson C. Parents' Judgments and Students' Self-Judgments of Empathy: The Structure of Empathy and Agreement of Judgments Based on the Interpersonal Reactivity Index (IRI). Eur J Psychol Assess. 2001;17:36-47.

108. Davis MH. Empathy: A social psychological approach. Boulder: Westview Press; 1994.

109. Westbury HR, Neumann DL. Empathy-related responses to moving film stimuli depicting human and non-human animal targets in negative circumstances. Biol Psychol. 2008;78:66-74.
110. Völlm BA, Taylor AN, Richardson P, Corcoran R, Stirling J, McKie S, et al. Neuronal correlates of theory of mind and empathy: a functional magnetic resonance imaging study in a nonverbal task. Neuroimage. 2006;29:90-98.

111. Nummenmaa L, Hirvonen J, Parkkola R, Hietanen JK. Is emotional contagion special? An fMRI study on neural systems for affective and cognitive empathy. Neuroimage. 2008;43:571580.

112. Reid C, Davis D, Horlin C, Anderson M, Baughman N, Campbell C. The kids' empathic development scale (KEDS): A multidimensional measure of empathy in primary school-aged children. Br J Dev Psychol. 2012;31:231-256.

113. Teding van Berkhout E, Malouff JM. The Efficacy of Empathy Training: A Meta-Analysis of Randomized Controlled Trials. J Couns Psychol. 2015;63:32-41.

114. Riess H, Kelley JM, Bailey RW, Dunn EJ, Phillips M. Empathy training for resident physicians: a randomized controlled trial of a neuroscience-informed curriculum. J Gen Intern Med. 2012;27:1280-1286.

115. Chiu Ming Lam T, Kolomitro K, Alamparambil FC. Empathy Training: Methods, Evaluation Practices, and Validity. J Multidiscip Eval. 2011;7:162-200.

116. Şahin M. An investigation into the efficiency of empathy training program on preventing bullying in primary schools. Child Youth Serv Rev. 2012;34:1325-1330.

117. Watson JC, Evelyn M. The role of empathy in promoting change. Psychother Res. 2013;24:286298.

118. Gerdes KE, Segal EA. A Social Work Model of Empathy. Adv Soc Work. 2009;10:114-127.

119. Moyers TB, Miller WR. Is low therapist empathy toxic? Psychol Addict Behav. 2013;27:878-884.

120. Hojat M, Louis DZ, Markham FW, Wender R, Rabinowitz C, Gonnella JS, Physicians' empathy and clinical outcomes for diabetic patients. Acad Med. 2011;86:359-364.

121. Vermeire E, Hearnshaw H, Van Royen P, and Denekens J. Patient adherence to treatment: three decades of research. A comprehensive review. J Clin Pharm Ther. 2001;26:331-342. 
122. Long ECJ, Angera JJ, Carter SJ, Nakamoto M, Kalso M. Understanding the one you love: A longitudinal assessment of an empathy training program for couples in romantic relationships. Fam Relat. 1999;48:235-242.

123. Telle NT, Pfister, HR. Not only the miserable receive help: Empathy promotes prosocial behaviour toward the happy. Curr Psychol. 2012;31:393-413.

124. Ang RP, Goh DH. Cyberbullying among adolescents: the role of affective and cognitive empathy, and gender. Child Psychiatry Hum Dev. 2010;41:397-97.

125. Salmon S. Teaching Empathy: The PEACE Curriculum. Reclaiming Children and Youth. 2003;12:167-173.

126. Campelia GD. Empathic Knowledge: The Import of Empathy's Social Epistemology. Soc Epistemol. 2017;31:530-544.

127. Bloom P. Against Empathy. New York: Harper Collins; 2016.

128. Prinz J. "Is Empathy Necessary for Morality?" In Coplan A. and Goldie P. eds. Empathy: Philosophical and Psychological Perspectives. New York: Oxford University Press; 2014. p. 211-229.

129. Code L. Rhetorical Spaces: Essays on Gendered Locations. New York: Routledge; 1995.
130. Bubandt N, Willerslev R. The Dark Side of Empathy: Mimesis, Deception, and the Magic of Alterity. Comp Stud Soc Hist. 2015;57:5-34.

131. Prinz J. Against Empathy. South J Philos. 2011;49:214-233.

132. Schiffrin HH, Liss M, Miles-McLean H, Geary KA, Erchull MJ, Tashner T. Helping or hovering? The effects of helicopter parenting on college students' well-being. J Child Fam Stud. 2014;23:548-557.

133. Young, A. (2016). "Empathic Cruelty and the Origins of the Social Brain." In: Suparna Choudhury S, Slaby J, ed. Critical Neuroscience: A Handbook of the Social and Cultural Context of Neuroscience. New York: Wiley-Blackwell; 2016. p. 159-176.

134. Hanich J, Wagner V, Shah M, Jacobsen T, Menninghaus W. Why we like to watch sad films. The pleasure of being moved in aesthetic experiences. Psychol Aesthet Creat Arts. 2014;8:130-143.

135. Breithaupt F. Die dunklen Seiten der Empathie. Berlin: Suhrkmap; 2017.

136. Zaki J, Ochsner K. The neuroscience of empathy: progress, pitfalls and promise. Nat Neurosci. 2012;15:675-680.

\section{Empatija: koncepti, teorije i neuroznanost}

Sažetak - Empatija je važan koncept u suvremenoj psihologiji i neuroznanosti u kojima su brojni autori posvećeni istraživanju tog fenomena. Većina njih se slaže u značaju koje ima empatija i njezinim pozitivnim utjecajima na međuljudske odnose, iako postoje i neki negativni aspekti empatije. Sa psihološkog i biološkog stanovišta, empatija je neophodna za ljudsko preživljavanje i uspješan život u društvenim grupama. Ovaj rad predstavlja pregled empatije, uključujući povijest koncepta počevši s pojmom Einfühlung, kao i početke proučavanja i definiranja empatije, suvremeni pristup, komponente empatije i njezinu evolucijsku i neuroznanstvenu pozadinu, mjerenje empatije, razvoj empatije kroz trening, i konačno, drugu stranu ovog uglavnom pozitivnog koncepta s obzirom na međuljudske odnose. Također smo naveli pregled prijedloga za daljnja istraživanja na ovom području.

Ključne riječi: empatija, afektivna empatija, kognitivna empatija, društveno-kognitivna neuroznanost, mjerenje empatije, trening empatije, sebična empatija 